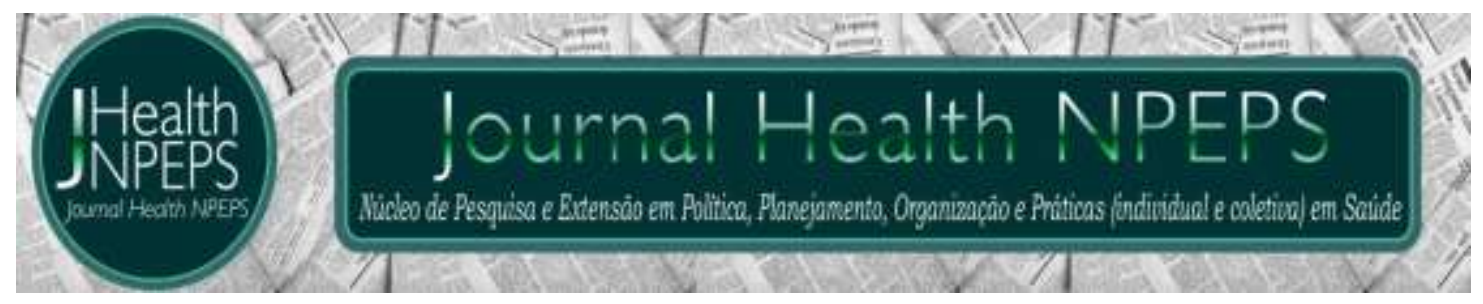

http://dx.doi.org/10.30681/252610104876

EDITORIAL

\title{
¡Hola! ¿Me escuchan? Reflexión desde la docencia virtual en enfermería en tiempos de pandemia
}

\section{Hello! Do you hear me? Reflection from virtual nursing teaching in times of pandemic}

\section{Olá! Me escutam? Reflexão do ensino de enfermagem virtual em tempos de pandemia}

\section{María de los Ángeles Rodríguez-Gázquez ${ }^{1}$}

Medio año después del inicio de la pandemia, es claro que el SARS CoV-2 afecta de alguna manera a cada habitante del planeta. Cuando el 13 de julio de este la Organización Mundial de la Salud dijo: "No habrá retorno a la normalidad en el futuro previsible"1, todos enfermeros cerramos los ojos, respiramos profundo y continuamos haciendo planes para resistir lo hiciera falta y para seguir dando lo mejor.

Las circunstancias generadas por la COVID-19 no solamente han afectado la forma como los enfermeros trabajamos en los hospitales y con la comunidad, también han ocasionado dificultades en las instituciones formadoras de recurso humano para que los procesos de enseñanza-aprendizaje sean significativos en la virtualidad.

Para docentes y estudiantes la adaptación en forma abrupta de la educación presencial a la virtual durante el confinamiento obligatorio no ha sido fácil. Los profesores de enfermería, carrera con una alta proporción de

${ }^{1}$ Enfermera. Doctora en Salud Pública. Profesora Titular de la Facultad de Enfermería de la Universidad de Antioquia. Medellín, Colombia. Email: maria.rodriguezg@udea.edu.co ORCID ID: https://orcid.org/0000$\underline{0002-4329-4286}$

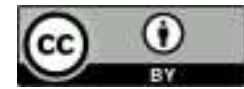

Este artigo está licenciado sob forma de uma licença Creative Commons Atribuição 4.0 Internacional, que permite uso irrestrito, distribuição e reprodução em qualquer meio, desde que a publicação original seja corretamente citada. 
asignaturas con componentes prácticos, no estábamos acostumbrados, ni teníamos los conocimientos suficientes para brindar las clases virtuales, por lo que la experiencia de aprender en tiempo récord a manejar las herramientas de software más la preparación de los temas de clase y su adaptación a las plataformas que son el vehículo para las actividades de docencia, se volvieron gran fuente de estrés y de trabajo adicional. Además de lo anterior, los profesores se quejan en todo el mundo de que durante las clases virtuales sincrónicas se sienten hablando solos por la baja participación de estudiantes, agregando que extrañan la anterior cercanía que tenían con ellos. Por otra parte, están los alumnos viviendo esta situación que parece interminable, una gran parte de ellos sin los recursos necesarios de dispositivos, Internet o de simplemente un sitio en casa donde puedan interactuar adecuadamente con su docente.

El momento actual, lleno de incertidumbre exige más que nunca que las universidades mostremos al mundo los resultados del compromiso con la formación de los futuros profesionales. Los docentes hemos tenido que ser más creativos y estamos trabajando por no ser resistentes a un cambio inevitable hacia la virtualidad y que, sin duda, hará grandes aportes a la formación profesional de calidad.

Es increíble la cantidad de metodologías que han desarrollado los docentes de Enfermería para alcanzar los objetivos de las asignaturas del currículo. Se han cambiado las tradicionales formas de enseñar y se ha tenido que innovar con el apoyo de las Tecnologías de la Información y Comunicación, no solamente para dar la clase teórica, sino también algunos temas de simulación, la consulta de enfermería y las actividades de educación a los pacientes, su familia y a los grupos comunitarios.

Sin embargo, sabemos que por la situación epidemiológica producida por la COVID-19 existen muchas limitaciones para que los estudiantes vuelvan a algunas prácticas que no hay forma de reemplazarlas con la virtualidad y que habrá que esperar el rumbo que tomen las cosas. Esto ha llevado a grandes discusiones en las escuelas de enfermería sobre si es posible reducir las horas de 
formación práctica en ciertas áreas temáticas, máxime de la urgencia manifiesta de la necesidad global de enfermeras, no solo para la atención de la pandemia, sino también para poder alcanzar la cobertura universal en salud, meta indispensable si se quieren alcanzar los Objetivos para el Desarrollo Sostenible del planeta ${ }^{2}$.

La pandemia del COVID-19 en pleno Año Internacional de la Enfermería ha dejado suficientemente claro el fundamental papel en la contribución sustancial que tiene nuestra profesión tiene en la salud de la población ${ }^{3}$. Es necesario que nos sigamos preparando para enfrentar los nuevos retos globales que nos exigen a los docentes volver a aprender a enseñar, comprometidos con el desafío de la formación de cada uno de nuestros alumnos para que brinden un cuidado de excelencia.

\section{REFERENCIAS}

1. World Health Organization WHO Director-General's opening remarks at the media briefing on COVID-19 - 13 July 2020 [Internet]. 2020 [citado 17 Aug 2020]. Disponible en: https://www.who.int/dg/speeches/detail/whodirector-general-s-opening-remarks-at-the-media-briefing-on-covid-19---13july-2020

2. World Health Organization. Year of the Nurse and the Midwife 2020 [Internet]. Geneve: WHO. 2019 [citado 17 Aug 2020]. Disponible en: https://www.who.int/en/news-room/campaigns/year-of-the-nurse-and-themidwife-2020

3. World Health Organization. 2020: International Year of the Nurse and the Midwife Report by the Director [Internet]. Geneve: WHO. 2019 [citado 17 Aug 2020]. Disponible

en: http://apps.who.int/gb/ebwha/pdf_files/WHA72/A72_54Rev1-en.pdf

Como citar: Rodríguez-Gázquez MLA. ¡Hola! ¿Me escuchan? Reflexión desde la docencia virtual en enfermería en tiempos de pandemia. J Health NPEPS. 2020; $5(2): 8-10$. 